\title{
Draining the Swamp
}

Airway clearance techniques are prescribed for a large variety of pulmonary diseases that are thought to be associated with mucus retention or poor sputum clearance. Just as airway clearance techniques are prescribed for diverse diseases, there are an equally large number of airway clearance techniques that include "classic" chest physiotherapy (chest percussion with or without postural drainage), directed cough, huff cough, active cycle of breathing, autogenic drainage, forced oscillation technique, and a number of positive expiratory pressure and vibratory devices. These techniques and devices are intended to assist in draining the airways of excess secretions and, by doing this, improving exercise tolerance and ventilation homogeneity, reducing atelectasis, preventing disease exacerbations, and slowing the rate of disease progression. ${ }^{1}$

Autogenic drainage is a system of breathing exercises developed for the treatment of cystic fibrosis by Jean Chevallier in $1967 .{ }^{2}$ It is a series of staged breaths at different lung volumes, starting with low-volume breaths from expiratory reserve volume that are repeated until secretions are felt to be "gathering" in the airways. Coughing is suppressed as a large volume of air is very slowly inhaled and then exhaled for 10-20 breaths until secretions are "collected" in more proximal airways. Finally, a series of vital capacity breaths are taken, followed by huff coughing to expel the secretions. The technique is complex and requires a great deal of patient understanding and cooperation to master. Autogenic drainage is thought to be as effective as chest physical therapy in acutely mobilizing secretions in patients with cystic fibrosis. ${ }^{3}$ Pfleger et $\mathrm{al}^{4}$ reported that positive expiratory pressure breathing and autogenic drainage both acutely improved pulmonary function test results in subjects with cystic fibrosis. Other studies suggest that autogenic drainage hastens airway clearance of inhaled radioisotope but has no significant effect on pulmonary function test results. ${ }^{5}$ There are few published studies evaluating autogenic drainage in subjects with diseases

Dr Rubin has disclosed no conflicts of interest.

Correspondence: Bruce K Rubin MEngr MD MBA FAARC, Children's Hospital of Richmond at VCU, 100 East Broad Street, Richmond, VA 23298. E-mail: bruce.rubin@ vcuhealth.org.

DOI: $10.4187 /$ respcare. 05511 other than cystic fibrosis, a common problem in all studies of airway clearance techniques. ${ }^{6}$

In this issue of RespiRatory CARE, in a paper by Poncin et $\mathrm{al}^{7}$ from Belgium, the home of autogenic drainage, it is reported that in subjects with non-cystic fibrosis bronchiectasis, lung clearance index (a measure of ventilation

See the Original Study on Page 524

homogeneity) improved after autogenic drainage, but improvement was only seen in $20 \%$ of the subjects studied. There was no improvement in pulmonary function other than a modest change in slow vital capacity. Perhaps the most important finding was that the 5 responders to autogenic drainage with improved lung clearance index expectorated significantly more sputum than the 19 who had no improvement in lung clearance index. Of the responders, 3 of 5 had primary ciliary dyskinesia, whereas this diagnosis was uncommon among the nonresponders (2 of 19).

Although these results are encouraging, it must be remembered that this was a study of a single airway clearance technique intervention. There are many studies that show that the application of airway clearance techniques can lead to immediate, short-term improvement in pulmonary function or expectorated sputum volume. Although airway clearance techniques are often prescribed, there is no evidence of benefit in asthma, pneumonia, atelectasis, bronchiolitis, COPD, chronic bronchitis, or non-cystic fibrosis bronchiectasis, and data regarding long-term benefit even in cystic fibrosis is limited. ${ }^{6}$ This is probably due, in part, to poor adherence to airway clearance techniques by patients with airway disease. ${ }^{8}$

From this study, ${ }^{7}$ it appears that the patients most likely to benefit from incorporating autogenic drainage into their daily routine are those with primary ciliary dyskinesia and significant sputum expectoration. There may also be a role for autogenic drainage in patients with other forms of bronchiectasis who also have significant expectoration. The key, of course, is not only successfully learning the technique, but using it consistently and correctly. Therefore, to drain the swamp of the airways, there must be sputum to drain, and the drainage must be an ongoing effort on the part of the patient. 


\section{EDITORIALS}

It takes more than a single application of a technique, or a quick campaign promise, to effectively drain a swamp.

Bruce K Rubin MEngr MD MBA FAARC

Department of Pediatrics

Children's Hospital of Richmond

Virginia Commonwealth University

Richmond, Virginia

\section{REFERENCES}

1. Rubin BK. Physiology of airway mucus clearance. Respir Care 2002; 47(7):761-768.

2. Chevallier J. Autogenic drainage. In: Lawson D, editor. Cystic fibrosis: horizons. Chichester, United Kingdom: John Wiley; 1984:235.

3. Robinson KA, McKoy N, Saldanha I, Odelola OA. Active cycle of breathing technique for cystic fibrosis. Cochrane Database Syst Rev 2010;(11):CD007862.
4. Pfleger A, Theissl B, Oberwaldner B, Zach MS. Self-administered chest physiotherapy in cystic fibrosis: a comparative study of highpressure PEP and autogenic drainage. Lung 1992;170(6):323-330.

5. Miller S, Hall DO, Clayton CB, Nelson R. Chest physiotherapy in cystic fibrosis: a comparative study of autogenic drainage and the active cycle of breathing techniques with postural drainage and percussion. Thorax 1995;50(2):165-169.

6. Strickland SL, Rubin BK, Drescher GS, Haas CF, O'Malley CA, Volsko TA, et al. AARC clinical practice guideline: effectiveness of nonpharmacologic airway clearance therapies in hospitalized patients. Respir Care 2013;58(12):2187-2193.

7. Poncin W, Reychler G, Leeuwerck N, Bauwens N, Aubriot AS, Nader C, et al. Short-term effect of autogenic drainage on ventilation inhomogeneity in adult subjects with stable non-cystic fibrosis bronchiectasis. Respir Care 2017;62(5):524-531.

8. Modi AC, Cassedy AE, Quittner AL, Accurso F, Sontag M, Koenig JM, Ittenbach RF. Trajectories of adherence to airway clearance therapy for patients with cystic fibrosis. J Pediatr Psychol 2010; 35(9):1028-1037. 